\title{
The Paradigm Shifts in the Management of Breast Cancer-Have We Finally Arrived?
}

\author{
Chintamani
}

Published online: 28 December 2013

(C) Association of Surgeons of India 2013

"In solving a problem of this sort, the grand thing is to be able to reason backwards. This is a very useful accomplishment, and a very easy one, but people do not practice it much." Sir Arthur Conan Doyle: A Study in Scarlet

It would be worthwhile tracing back the historical events as they happened in the history of breast cancer to understand the progress made in its management. Every generation saw a new paradigm emerge that looked the best for the moment and was adapted. So much has changed in the management of this cancer, especially in the last century that if one claims one knows all about it, one knows nothing about it.

The story of breast cancer can broadly be divided in to:

- The Pre-Halsteadean Era [1-6]:

Ancient Egypt

Ancient Egyptians were the first to note the disease more than 3,500 years ago. One nameless ancient Egyptian surgeon in 460 B.C. described "bulging tumors" in the breast and stated that "there is no cure." Both the Edwin Smith and George Ebers papyri contain descriptions of conditions that are consistent with modern understanding of breast cancer. Column VIII of The Edwin Smith Surgical Papyrus, which has a copy of the first document, describes cancer of the breast [circa 3000 BC].

Greeks-a systemic disease!

Hippocrates believed that cancer was caused by excess of black bile, or "melonchole" and believed that the disease is systemic rather than local in presentation and behavior. He named cancer "karkinos," a Greek word for "crab," because the tumors seemed to have tentacles, like the legs of a crab. Hippocrates considered surgery dangerous in these patients, "those who had the tumor

Chintamani $(\bowtie)$

Vardhman Mahvir Medical College, Safdarjang Hospital,

New Delhi, India

e-mail: chintamani7@rediffmail.com excised "perished" quickly; while those who are not excised lived longer (Olsen 2002)."

- The Halsteadean Era

This era was aptly named after the great surgeon William S. Halstead who had trained and learnt his skills in Europe. He brought about a revolutionary change in the practice and teaching of science and art of surgery in the USA by starting the 6-year residency program. He brought surgery to the center of the management of most solid cancers. His radical surgery stood the test of time for nearly a century in spite of various challenges and less radical treatment protocols offered by his contemporaries and detractors like GW Crile.

"As effecting the ultimate result, the variety of the cancer, the time elapsed since its appearance, the degree of outlying involvement, the activity of the gland (lactation, age of patient), the thoroughness of the operation, are important Factors" [Halstead's presentation before American Surgical Association, May 8, 1907].

Halstead highlighted the fact that breast cancer and for that matter most cancers follow a predictable pattern of spread from one to the next echelon. An en bloc removal of all echelons could thus achieve a cure. This formed the basis of his extra- or supraradical surgery for breast cancer that got rightly named after him. In the presentation of his data before the American Surgical Association, May 8, 1907, it could be observed that patients with axillary lymph nodes did not do well after 5 years of surgery as compared to those with no nodes. Lymph nodes were thus understood as important predictors of outcome.

GW Crile (early twentieth century), however, remarked that "if a cancer treatment required removal of muscles for cure, it was too late in the day for any effective treatment." This supraradical surgery was thus challenged even while it was becoming the standard of care in breast cancer. Halstead went on to suggest that supraclavicular neck dissection should 
be part of this surgery along with clearance of internal mammary nodes, (making breast cancer treatment "sometimes" worse than the disease). After having reached a plateau of success in terms of outcome, it could be realized that it could not be improved any further and patients with locally advanced disease continued to die.

Quoting Niels Bohr, "Opposite of a correct statement is a false statement, the opposite of a profound truth well be another profound truth." Halstead and his theory of a predictable spread of breast cancer from one to the next echelon forms the very basis of sentinel lymph node biopsy (SLNB) in the present era. The concept that cancer spreads in a predictable manner from level-I to level-II and level-III lymph nodes in more than $90 \%$ cases forms the very basis of SLNB. However, most patients in spite of an optimum/aggressive local surgery die due to metastatic disease (distant failure) making breast cancer a systemic disease. The truth therefore lies somewhere in the middle.

\section{- Post Halsteadean era}

The treatment strategies having reached a plateau following supraradical approach in the management of breast cancer, it became evident that a combination of systemic and local treatments (middle path!) would be essential to improve the outcome any further. Some of the highlights of this era included surgeons like George Thomas Beatson who highlighted the role of oophorectomy (hormones) as the basis of occurrence of breast cancers. The first targeted therapy for breast cancer in the form of hormone modulation was thus discovered. Hormone therapy is still the standard of care in hormone receptor-positive $(\mathrm{ER}+, \mathrm{PR}+)$ patients.

Colonel Sir George Thomas Beatson British physician

1848-1933 known as the father of endocrine ablation in cancer management. He compared the histologic changes in the lactating breast after pregnancy in sheep with those seen in carcinoma.

\section{Radiations and Cancer-The Pendulum Swings Again [5-7]}

We owe to Madam Marie Curie, an eminent Nobel Laureate, the gift of radiations to science which led to the emergence of a new treatment modality "radiotherapy." Radiations became an essential part of the management of solid cancers, bringing about yet another paradigm shift in the management of breast cancer and cancers in general. Radiations continued to be used in all cancers based more on hit and trial rather than an evidence-based and a scientifically reproducible approach. Finally, the role got more precisely defined with many trials to define the role of this alternate knife in the management of breast cancer.

\footnotetext{
The evolution of breast cancer management; Pendulum swings, paradigms shifts! The en 'light'ening - The radiations!! - M.C. Whirter

M.C. Whirter was among the first to propose and do a simple mastectomy as a stand-alone surgery to breast cancer. "Do less surgery, and add it up with some radiation to increase the local control." The axilla, he professed, "would be better treated by radiotherapy and opened flood gates of conservative surgeries in breast cancer. The fact that one can omit one of the most critical components of the so called radical surgery, and cover it up with radiation stimulated many minds to go further down the conservative path. All new mantra was emerging, and with it, the pendulum was ready for another great swing that will take it farther away from Halstedian heroics!"
}

\section{The Fisher's Paradigm—a Systemic Disease}

The randomized trial - National Surgical Adjuvant Breast and Bowel Project (NSABP) B-04-begun in 1971, about 10 years after Dr. Fisher and his brother, pathologist Edwin R. Fisher, began an extensive analysis of breast tumor metastases.

NSABP-B-04, 06 - the Major Paradigm Shift of the Twentieth Century [7-9]

Revealed and highlighted in an era of radicality, the fact that women who die from breast cancer almost always do so because of micrometastases.

B-04 laid the foundation for systemic therapy and neoadjuvant chemotherapy (NACT). It was finally accepted that breast cancer is a systemic disease rather than a local disease of the breast. This perhaps was the most important study on breast cancer in the twentieth century [].

\section{B-04- the major paradigm shift of the twentieth Century}

The study enrolled 1,700 women grouped into the following:

- Group I: 1,079 with clinically negative axillary nodes who underwent radical mastectomy.

- Group II: total mastectomy without axillary dissection but with postoperative radiation, or total mastectomy with axillary dissection if their nodes became clinically positive.

- Group III: 586 women with clinical positive axillary nodes who underwent radical mastectomy.

- Group IV: total mastectomy, without axillary dissection but with postoperative radiation.

Observations: No significant survival differences were observed among the three groups of women with clinically negative nodes or between the two groups with clinically positive nodes. The findings further confirmed that there is no therapeutic advantage to the Halsted radical mastectomy.

New England Journal of Medicine (2002;, 3478:567-575) on the 25-year results of the National Surgical Adjuvant Breast and Bowel Project (NSABP) study comparing radical mastectomy with total mastectomy, with or without radiation, was rich in historical significance. B-04 provided a rationale for NSABP B-06, which compared total mastectomy to lumpectomy, and other tissue-sparing procedures, including sentinel node biopsy, which the NSABP evaluated later. - Dr. B Fisher 


\section{Protocol B-06 [7, 8]}

Compared Segmental Mastectomy and Axillary Dissection With and Without Radiation of the Breast and Total Mastectomy and Axillary Dissection. To determine in patients with or without clinical axillary node involvement who may be amenable to segmental mastectomy (SM) whether:

1. Simple mastectomy and axillary dissection with or without radiation of the breast is equivalent to total mastectomy plus axillary dissection?

2. Could a cosmetically acceptable preservation of the breast in a subset of patients with primary cancer be achieved without unfavorably influencing treatment failure and mortality rates as well as morbidity?

3. Could an evidence be obtained to indicate the clinical significance of microscopic multifocal tumor in the breast?

Edward Romond laid the Foundation for Systemic Therapy and also introduced the concept of neo-adjuvant chemotherapy to manage the micrometastases before the local therapy in the form of surgery or radiotherapy.

\section{Neo-Adjuvant Chemotherapy_Another Paradigm Shift [10-15]}

With an understanding that breast cancer is essentially a systemic disease, NACT came in to vogue. This therapy was expected to treat micrometastases that did not show up at presentation. Neo-adjuvant chemotherapy also provides vital information on tumor behavior by providing an in vivo chemosensitivity test of a particular regime. It also helped detect patients where pathological complete response (pCR) could be achieved which is a surrogate marker of outcome. This therapy also helped in downsizing some really large tumors making them amenable to curative surgery (R0 resection). Meanwhile, various predictive and prognostic biomarkers were being evaluated to predict response to neo-adjuvant chemotherapy in order to tailor the therapy and avoid chemotoxicity in nonresponders. Besides the routine ER/PR and HER-2 neu expression, various other markers were being studied to study the tumor behavior and response to therapies to further tailor the regimes. Molecular biology and the related research indicated that a better understanding of this cancer at cellular level was mandatory to improve the outcomes any further.

\section{Conservative Surgery for Breast Cancer [7-9]}

Umberto Veronesi from Milan is considered the founder of breast-conserving surgery. He was among the first to perform quadrantectomy that challenged the earlier dogma that cancer could only be treated with aggressive surgery. Addressal of axilla was also undergoing a paradigm shift in the form of sentinel lymph node biopsy instead of morbid routine axillary lymph node dissection in clinically node-negative axillae. SLNB has now become the standard of care in node-negative axillae especially in early breast cancer [B-32-Paradigm shift in the addressal of axilla-SLNB!! - A Randomized, Phase III Clinical Trial to Compare Sentinel Node Resection to Conventional Axillary Dissection in Clinically Node-Negative Breast Cancer Patients]. The options to use SLNB in locally advanced breast cancer after neo-adjuvant chemotherapy are also being explored and may actually become the standard of care in future [16-19].

\section{Can Axilla be Spared in Patients with Positive Sentinel Node? [16, 17]}

[Axillary Dissection vs No Axillary Dissection in Women with Invasive Breast Cancer and Sentinel Node Metastasis: a Randomized Clinical Trial [Z0011] Armando E. Giuliano, JAMA. 2011;305(6):569-575.

The findings from Z0011 document the high rate of locoregional control achieved with modern multimodality therapy, even without axillary lymph node dissection (ALND). Targeted enrollment was 1,900 women with final analysis after 500 deaths, but the trial closed early because mortality rate was lower than expected]

This trial concluded that among patients with limited SLN metastatic breast cancer treated with breast conservation and systemic therapy, the use of SLND alone when compared with ALND did not result in inferior survival. Although the trial did have its limitations in the process of randomization and accrual, it still is a step in the direction of achieving a goal where the axilla could simply be observed in a select group with minimal or no axillary burden. The trials (AMAROS trial) sparing axillary dissection and/or replacing it with radiations are on to make the management of axillae in breast cancer minimally invasive [17].

\section{Targeted Therapy [15-19]}

While the local treatment is becoming more and more conservative, the systemic treatment is getting more and more aggressive. This is associated with unacceptable toxicity and collateral damage, for little or no extra gain in terms of outcome. While the various signal pathways were being studied for developing targeted therapy that would work with minimal collateral damage, search for the proverbial "magic bullet" is still on. Tamoxifen was the first targeted therapy that was used in patients with positive hormone receptors expression. Aromatase inhibitors in postmenopausal women were found to be more effective 
selective hormone modulators. Trastuzumab in patients with HER-2Neu expression is increasingly being used as a targeted therapy that has changed the outcome remarkably in adjuvant and also in neo-adjuvant setting. The surgeon is thus forced and getting lured in to tumor biology laboratory to study the minute and suttle cellular changes affecting the behavior and outcome in breast cancer, which in itself is a true paradigm shift. The biological classification of breast cancer rather than the anatomical classification is now being considered more apt as it is no longer simply about the size of the cancer. There is indeed more to it than meets the eye.

\section{The Indian Breast Cancer [19-23]}

The Indian breast cancer indeed behaves differently from its western counterpart and needs to be addressed differently. Most cancers are still locally advanced at presentation and there is lack of any standardized approach to their management. Unlike in the west where the incidence keeps rising with age, touching the peak in 60 s, the Indian breast cancer shows two peaks of occurrence, one in 40s and the other in $60 \mathrm{~s}$. The younger cancer has been found to be more aggressive with a higher incidence of triple negatives (ER negative, PR negative, HER-2Neu negative), BRCA-I and II mutations, and larger size with higher incidence of axillary lymph nodes $[19,20]$. The delays in presentation have traditionally been blamed on the patients (fatalistic attitude, illiteracy, lack of awareness, etc.) and lack of screening programs. However, in a study conducted by the author and his team, it has been found to be primarily due to the providers. There is therefore a need to find an Indian solution to Indian problems [20-23].

This journey is symbolic of the efforts made over the years to conquer cancer in general and breast cancer in particular. Are we where the Greeks were (a systemic disease!)? The answer would be a clear "no" as we understand the behavior of this cancer much better today. But we still have miles to go (especially in the developing world) before we start believing that we have truly arrived.

\section{References}

1. Encyclopedia Britannica (1978), 15th ed. Encyclopedia Britannica, Inc. Chicago: Encyclopedia Britannica Inc., Macropedia 11:823

2. Breasted JH, editor. The Edwin Smith surgical papyrus. Chicago, IL: The University of Chicago Press; 1930, Special Edition. 1984. The Classics of surgery library. Division of gryphon editions, Ltd. Birmingham (AB). Frontispiece

3. De Moulin D (1983) A short history of breast cancer. Martinus Nijhoff, Boston, pp 1-107

4. Lewison EF (1950) Saint Agatha the patron saint of diseases of the breast in legend and art. Bull History Med 24:409-420
5. Lyons AS, Petrucelli RJ (1978) Medicine. An illustrated history. Harry N Abrams, New York, pp 294-317

6. Fisher B, Anderson S, Bryant J et al (2002) Twenty-year follow-up of a randomized trial comparing total mastectomy, lumpectomy, and lumpectomy plus irradiation for the treatment of invasive breast cancer. N Engl J Med 347(16):1233-1241

7. Fisher ER, Anderson S, Tan-Chiu E et al (2001) Fifteen-year prognostic discriminants for invasive breast carcinoma: National Surgical Adjuvant Breast and Bowel Project Protocol-06. Cancer 91(8 Suppl): $1679-1687$

8. Fisher B, Anderson S, Redmond CK et al (1995) Reanalysis and results after 12 years of follow-up in a randomized clinical trial comparing total mastectomy with lumpectomy with or without irradiation in the treatment of breast cancer. N Engl J Med 333(22): 1456-1461

9. Fisher ER, Anderson S, Redmond C et al (1992) Ipsilateral breast tumor recurrence and survival following lumpectomy and irradiation: pathological findings from NSABP protocol B-06. Semin Surg Oncol 8(3):161-166

10. Mishra AK, Agrawal U, Negi S, Bansal A, Mohil R, Chintamani C, Bhatnagar A, Bhatnagar D, Saxena S (2012) Expression of androgen receptor in breast cancer $\&$ its correlation with other steroid receptors \& growth factors. Indian J Med Res 135(6):843-852

11. Chintamani, Singh JP, Mittal MK, Saxena S, Bansal A, Bhatia A, Kulshreshtha P (2005) Role of p-glycoprotein expression in predicting response to neoadjuvant chemotherapy in breast cancer - a prospective clinical study. World J Surg Oncol 3:61

12. Singh LC, Chakraborty A, Mishra AK, Devi TR, Sugandhi N, Chintamani C, Bhatnagar D, Kapur S, Saxena S (2012) Study on predictive role of $\mathrm{AR}$ and EGFR family genes with response to neoadjuvant chemotherapy in locally advanced breast cancer in Indian women. Med Oncol 29(2):539-546

13. Chintamani, Kulshreshtha P, Chakraborty A, Singh L, Mishra AK, Bhatnagar D, Saxena S (2010) Androgen receptor status predicts response to chemotherapy, not risk of breast cancer in Indian women. World J Surg Oncol 8:64

14. Chintamani, Rekhi B, Bansal A, Bhatnagar D, Saxena S (2010) Expression of E-Cadherin in breast carcinomas and its association with other biological markers - a prospective study. Indian J Surg Oncol 1(1):40-46. doi:10.1007/s13193-010-0010-1

15. Chintamani, Jha BP, Bhandari V, Bansal A, Saxena S, Bhatnagar D (2007) The expression of mismatched repair genes and their correlation with clinicopathological parameters and response to neoadjuvant chemotherapy in breast cancer. Int Semin Surg Oncol 4:5

16. Giuliano AE, Hunt KK, Ballman KV, Beitsch PD, Whitworth PW, Blumencranz PW, Leitch AM, Saha S, McCall LM, Morrow M (2011) Axillary dissection vs no axillary dissection in women with invasive breast cancer and sentinel node metastasis: a randomized clinical trial. JAMA 305(6):569-575. doi:10.1001/jama.2011.90

17. Rutgers EJ, Donker M, Straver ME (2013) Radiotherapy or surgery of the axilla after a positive sentinel node in breast cancer patients: final analysis of the EORTC AMAROS trial (10981/22023). J Clin Oncol. 31

18. Chintamani, Tandon M, Mishra A, Agarwal U, Saxena S (2011) Sentinel lymph node biopsy using dye alone method is reliable and accurate even after neo-adjuvant chemotherapy in locally advanced breast cancer - a prospective study. World J Surg Oncol 9:19

19. Chintamani (2012) Sentinel lymph node biopsy in breast cancershould it be the standard of care in India? Indian J Surg 74(3):205207

20. Saxena S, Rekhi B, Bansal A, Bagga A, Chintamani, Murthy NS (2005) Clinico-morphological patterns of breast cancer including family history in a New Delhi hospital, India - a cross-sectional study. World J Surg Oncol 3:67

21. Chintamani, Tuteja A, Khandelwal R, Tandon M, Bamal R, Jain S, Narayan N, Srinivas S, Kumar Y (2011) Patient and provider delays 
in breast cancer patients attending a tertiary care centre: a prospective study. JRSM Short Rep 2(10):76

22. Chakraborty A, Murthy NS, Chintamani C, Bhatnagar D, Mohil RS, Sharma PC, Saxena S (2007) CYP17 gene polymorphism and its association with high-risk north Indian breast cancer patients. J Hum Genet 52(2):159-165
23. Saxena S, Chakraborty A, Kaushal M, Kotwal S, Bhatanager D, Mohil RS, Chintamani C, Aggarwal AK, Sharma VK, Sharma PC, Lenoir G, Goldgar DE, Szabo CI (2006) Contribution of germline BRCA1 and BRCA2 sequence alterations to breast cancer in Northern India. BMC Med Genet 7: 75 